Research Article

\title{
Pollution Characteristics and Risk Assessment of Heavy Metal Elements in Sediment in the West Lake of Hengshui Lake
}

\author{
Zhongqiang Zhang $\mathbb{D}^{1},{ }^{1}$ Shuzhen Wei, ${ }^{2}$ and Jianxiao Liu ${ }^{3}$ \\ ${ }^{1}$ Department of Applied Chemistry, Hengshui University, Hengshui, Hebei 053000, China \\ ${ }^{2}$ Wetland Conservation Research Center, Hengshui University, Hengshui, Hebei 053000, China \\ ${ }^{3}$ Department of Physics, Hengshui University, Hengshui, Hebei 053000, China \\ Correspondence should be addressed to Zhongqiang Zhang; zhangzhongqiang@126.com
}

Received 22 July 2021; Revised 21 August 2021; Accepted 2 September 2021; Published 13 September 2021

Academic Editor: Wei Liu

Copyright ( 92021 Zhongqiang Zhang et al. This is an open access article distributed under the Creative Commons Attribution License, which permits unrestricted use, distribution, and reproduction in any medium, provided the original work is properly cited.

\begin{abstract}
21 sampling points were set in the West Lake of Hengshui Lake including 20 fish ponds and 1 natural pond to analyze the contents distribution of heavy metal elements including $\mathrm{Cr}, \mathrm{Zn}, \mathrm{Pb}, \mathrm{Cu}, \mathrm{Cd}, \mathrm{Hg}$, As, and $\mathrm{Sb}$ in sediment. The degree of heavy metal pollution was evaluated by the geoaccumulation index $\left(I_{\text {geo }}\right)$ method. The results showed that the concentrations of $\mathrm{Cr}, \mathrm{Zn}, \mathrm{Pb}, \mathrm{Cu}, \mathrm{Cd}$, and $\mathrm{Hg}$ at in all sampling points of the fish ponds were lower than soil risk screening values of agricultural land in soil environmental quality: risk control standard for soil contamination of agricultural land (trial) (GB 15618-2018). The concentrations of As at 5 sampling points were higher than soil risk screening values and lower than soil risk control values of agricultural land in GB 156182018. The concentrations of Sb were lower than soil risk screening values of construction land in soil environmental quality: risk control standard for soil contamination of development land (trial) (GB 36600-2018). The evaluation results of the geoaccumulation index method showed that the pollution degrees of $\mathrm{Cd}, \mathrm{Pb}$, and $\mathrm{Hg}$ were moderately contaminated in general, the pollution degree of $\mathrm{Cu}$ was uncontaminated to moderately contaminated in general, the pollution degrees of $\mathrm{Cr}$ and As were uncontaminated to moderately contaminated in some sampling points, and $\mathrm{Zn}$ and $\mathrm{Sb}$ could be regarded as uncontaminated in sediment of the fish ponds in the West Lake of Hengshui Lake. Otherwise, the average contents of other heavy metal elements in sediment of the fish ponds in the West Lake of Hengshui Lake were higher than the background value of soil in Hebei Province (BVSH) except for $\mathrm{Zn}$ and $\mathrm{Sb}$. The average contents of seven heavy metal elements in sediment of the natural pond in the West Lake of Hengshui Lake were lower than BVSH except for Cr. The result can be regarded as no pollution in the natural pond because the values of $I_{\text {geo }}$ were all lower than 0 . The heavy metal pollution in the sediment of the West Lake of Hengshui Lake may be due to the introduction of feeding. The water environment of the West Lake of Hengshui Lake can be effectively improved by cleaning up the sediment of fish ponds and "returning fishing to wetland."
\end{abstract}

\section{Introduction}

The heavy metal pollution has the characteristics of strong toxicity, easy accumulation, and nondegradation, which is one of the key points in the current environmental pollution prevention and control work. The sediment in the lake usually has a strong accumulation effect on heavy metal elements because heavy metal elements in lake can be enriched in sediment through a variety of biological and physicochemical processes. The contents of the heavy metal elements in sediment in lake are often much higher than that in the water itself, which may be hundreds or even tens of thousands of times of its content in the water. The heavy metal elements in sediment may be released into water under the certain conditions. It may lead to the secondary pollution of water body [1-5]. The polluted condition of sediment is one of the important factors to evaluate the quality of lake water environment $[6,7]$. So, it is great significance to study the endogenous pollution release of heavy metal in lake water environment through the characteristics, and risk of heavy metal pollution was assessed in lake sediment. 
Hengshui Lake is located in Hengshui City, Hebei Province, with an area of about $75 \mathrm{~km}^{2}$. It is a typical inland fresh water lake. It is the main source of drinking water and industrial and agricultural production in Hengshui City and its surrounding areas. It is also a gathering place of animals and plants in the north temperate zone and a transit place for rare and endangered migratory birds. The maximum storage capacity is 188 million $\mathrm{m}^{3}$. It is the first National Wetland Nature Reserve in North China Plain.

Hengshui Lake is divided into East Lake and West Lake. The West Lake covers an area of about $32.5 \mathrm{~km}^{2}$, with scattered water surface including many fish ponds and a natural pond. Due to historical reasons, there is a risk of heavy metal enrichment in sediment. In recent years, there have been studies on the pollution characteristics and ecological risk of heavy metal elements in the sediment of Hengshui Lake [8-11] and mainly focusing on the East Lake, while the study on the West Lake of Hengshui Lake has not been reported. In this study, the sediment of the West Lake of Hengshui Lake has been sampled and analyzed, and heavy metal pollution in sediment has been evaluated by using the geoaccumulation index $\left(I_{\text {geo }}\right)$ method, so as to provide scientific basis for the effective control of heavy metal pollution, ecological environment protection, and risk management and control of Hengshui Lake.

\section{Materials and Methods}

2.1. Sampling Point Setting. The water area of the West Lake of Hengshui Lake is relatively scattered, and the distribution is uneven including many fish ponds and a natural pond. Therefore, according to the geographical location of the West Lake of Hengshui Lake, 21 sampling points had been set up in the West Lake of Hengshui Lake, including 20 fish ponds and 1 natural pond. The study area is located at longitude $115.5511726-115.580819^{\circ} \mathrm{E}$ and latitude 37.56 $968-37.637332^{\circ} \mathrm{N}$.

2.2. Sample Collection and Analysis. According to the field investigation of the sediment and the disturbance in the West Lake of Hengshui Lake, 21 sampling points were selected in the West Lake of Hengshui Lake. The water depth of the sampling points is $1-5 \mathrm{M}$. The TC-600 the grab dredger was used to collect the sediment samples with the depth of $0-50 \mathrm{~cm}$, the sampling area was $50 \times 50 \mathrm{~cm}^{2}$, and the sampling points were located by GPS, July 15-17, 2019. The sediment volume of each sampling point was about 1-2 L. The collected sediment samples were sealed and stored in polyethylene plastic bags and transported back to the laboratory for low temperature storage.

The sediment samples were air-dried. The dried sediment samples were homogenized with an agate mortar and sieved in a $0.5 \mathrm{~mm}$ mesh nylon sieve to obtain a fine homogeneous powder in the laboratory. Then, the samples were dried in an oven at $105^{\circ} \mathrm{C}$ to constant weight for the experiment.

The sediment samples were digested by a microwave digester (Model Mars6, CEM, U.S.A). The contents of Cr,
$\mathrm{Zn}, \mathrm{Pb}, \mathrm{Cu}, \mathrm{Cd}$, and $\mathrm{Sb}$ were determined by the atomic absorption spectrometry (Model TAS-990, Beijing Puxi General Instrument Co., Ltd., China), and the contents of $\mathrm{Hg}$ and As were determined by the atomic fluorescence spectrometry (Model SA7/5, Beijing Puxi General Instrument Co., Ltd., China).

2.3. Data Processing and Assessment Methods. In 1969, German scholar Mulr proposed the geoaccumulation index $\left(I_{\text {geo }}\right)$ method [12], which was widely used to evaluate heavy metal pollution in water and sediment. Therefore, the geoaccumulation index method has been used to evaluate the heavy metal pollution degree of the West Lake of Hengshui Lake in this study.

The calculation formula of the geoaccumulation index method is expressed as

$$
I_{\text {geo }}=\log \left(\frac{C_{i}}{k B_{i}}\right),
$$

where $C_{i}$ is the content of the element $i$ in sediment (unit: $\mathrm{mg} / \mathrm{kg}$ ), and $B_{i}$ is the geochemical background value of the element $i$. In this study, the background value of soil heavy metal elements content in Hebei Province (BVSH) [13] was used as the reference value. Coefficient $k$ is the rectification coefficient due to the difference of the regional background value, generally 1.5. According to the value of $I_{\text {geo }}$, the heavy metal pollution degrees are divided into 7 classes (Table 1).

2.4. Statistical Analysis. The experimental data were processed by Excel software and were plotted by ArcGIS 10.3 software.

\section{Results and Discussion}

3.1. Distribution Characteristics of Heavy Metal Elements in the Sediment of the West Lake of Hengshui Lake. The contents of heavy metal elements in the sediment of the West Lake of Hengshui Lake are given in Table 2. Based on the background value of the soil heavy metal elements content in Hebei Province (BVSH), the pollution of eight heavy metal elements in the sediment of the West Lake of Hengshui Lake was evaluated. In natural ponds, the contents of the other seven heavy metal elements were all lower than BVSH except for $\mathrm{Cr}$.

In the fish ponds sediment, only the average contents of $\mathrm{Zn}$ and $\mathrm{Sb}$ were lower than BVSH. In all sampling points, the contents of $\mathrm{Sb}$ were all lower than BVSH, while the contents of $\mathrm{Zn}$ were slightly higher than BVSH at 7 sampling points. The contents of $\mathrm{Cr}, \mathrm{Pb}, \mathrm{Cu}, \mathrm{Cd}, \mathrm{Hg}$, and As were higher than BVSH. The average contents of $\mathrm{Cd}, \mathrm{Hg}$, and $\mathrm{Pb}$ were 2.37, 2.24, and 2.00 times of BVHB, respectively. It indicated that the pollution of $\mathrm{Cd}, \mathrm{Hg}$, and $\mathrm{Pb}$ in the sediment of fish ponds in the West Lake of Hengshui Lake was relatively serious. The average contents of $\mathrm{Cu}, \mathrm{Cr}$, and As were 1.72, 1.47, and 1.47 times of BVSH, respectively. It indicated that there was slight pollution of $\mathrm{Cu}, \mathrm{Cr}$, and $\mathrm{As}$ in the sediment of fish ponds in the West Lake of Hengshui Lake. 
TABLE 1: $I_{\text {geo }}$ and classification of sediment pollution degree.

\begin{tabular}{lccccccc}
\hline$I_{\text {geo }}$ & $\leqq 0$ & $0 \sim 1$ & $1 \sim 2$ & $2 \sim 3$ & $3 \sim 4$ & $4 \sim 5$ & $>5$ \\
\hline Class & 0 & 1 & 2 & 3 & 4 & 5 & 6 \\
$\begin{array}{l}\text { Pollution } \\
\text { degree }\end{array}$ & Uncontaminated & $\begin{array}{c}\text { Uncontaminated to } \\
\text { moderately } \\
\text { contaminated }\end{array}$ & $\begin{array}{c}\text { Moderately } \\
\text { contaminated }\end{array}$ & $\begin{array}{c}\text { Moderately to } \\
\text { heavily } \\
\text { contaminated }\end{array}$ & $\begin{array}{c}\text { Heavily } \\
\text { contaminated }\end{array}$ & $\begin{array}{c}\text { Heavily to } \\
\text { extremely } \\
\text { contaminated }\end{array}$ & $\begin{array}{c}\text { Extremely } \\
\text { contaminated }\end{array}$ \\
\hline
\end{tabular}

TABLE 2: Contents of heavy metal elements in the sediment at various sampling points in the West Lake of Hengshui Lake (mg/kg).

\begin{tabular}{|c|c|c|c|c|c|c|c|c|c|c|}
\hline Sampling point & $\begin{array}{c}\text { Longitude } \\
\left({ }^{\circ} \mathrm{E}\right)\end{array}$ & $\begin{array}{c}\text { Latitude } \\
\left({ }^{\circ} \mathrm{N}\right)\end{array}$ & $\mathrm{Cr}$ & $\mathrm{Zn}$ & $\mathrm{Pb}$ & $\mathrm{Cu}$ & $\mathrm{Cd}$ & $\mathrm{Hg}$ & As & $\mathrm{Sb}$ \\
\hline 1 & 115.57972 & 37.637332 & 110.8 & 81.4 & 45.9 & 39.5 & 0.22 & 0.067 & 20.8 & 0.19 \\
\hline 2 & 115.580235 & 37.632706 & 96.3 & 64.2 & 38.6 & 44.7 & 0.13 & 0.092 & 16.4 & 0.08 \\
\hline 3 & 115.580819 & 37.625911 & 128.6 & 82.3 & 58.9 & 63.1 & 0.37 & 0.112 & 23.2 & 0.13 \\
\hline 4 & 115.577401 & 37.615455 & 74.7 & 53.8 & 25.6 & 36.5 & 0.19 & 0.043 & 14.4 & 0.07 \\
\hline 5 & 115.578115 & 37.613281 & 86.4 & 62.7 & 45.1 & 29.9 & 0.13 & 0.051 & 13.8 & 0.11 \\
\hline 6 & 115.577711 & 37.61342 & 71.3 & 58.5 & 31.6 & 40.3 & 0.17 & 0.038 & 15.3 & 0.09 \\
\hline 7 & 115.576741 & 37.613887 & 88.6 & 71.5 & 28.9 & 31.3 & 0.16 & 0.042 & 14.9 & 0.15 \\
\hline 8 & 115.57612 & 37.613968 & 94.2 & 58.7 & 37.6 & 48.8 & 0.18 & 0.097 & 18.1 & 0.12 \\
\hline 9 & 115.57448 & 37.614382 & 102.1 & 79.5 & 50.8 & 39.6 & 0.15 & 0.093 & 22.6 & 0.16 \\
\hline 10 & 115.572681 & 37.608833 & 79.4 & 51.3 & 29.8 & 31.2 & 0.11 & 0.082 & 16.2 & 0.06 \\
\hline 11 & 115.570792 & 37.614233 & 81.5 & 69.6 & 38.7 & 34.1 & 0.22 & 0.098 & 15.5 & 0.09 \\
\hline 12 & 115.575772 & 37.608444 & 86.3 & 75.2 & 26.5 & 22.3 & 0.14 & 0.049 & 13.9 & 0.05 \\
\hline 13 & 115.575105 & 37.609114 & 78.6 & 79.7 & 31.4 & 32.8 & 0.18 & 0.055 & 14.8 & 0.07 \\
\hline 14 & 115.569049 & 37.607871 & 139.7 & 79.5 & 68.3 & 59.5 & 0.35 & 0.151 & 28.3 & 0.31 \\
\hline 15 & 115.5511726 & 37.56968 & 162.6 & 95.8 & 76.4 & 53.1 & 0.48 & 0.134 & 30.4 & 0.26 \\
\hline 16 & 115.573043 & 37.596982 & 103.6 & 62.1 & 38.6 & 23.3 & 0.29 & 0.081 & 17.4 & 0.12 \\
\hline 17 & 115.570848 & 37.592124 & 115.9 & 76.4 & 53.4 & 31.4 & 0.32 & 0.126 & 25.8 & 0.14 \\
\hline 18 & 115.570396 & 37.591182 & 97.1 & 63.2 & 50.8 & 29.6 & 0.21 & 0.064 & 30.7 & 0.11 \\
\hline 19 & 115.569973 & 37.587342 & 127.5 & 87.6 & 46.1 & 33.2 & 0.34 & 0.087 & 28.2 & 0.35 \\
\hline 20 & 115.571514 & 37.577032 & 89.3 & 58.4 & 35.7 & 23.8 & 0.12 & 0.054 & 19.7 & 0.09 \\
\hline Average & & & 100.725 & 70.570 & 42.935 & 37.400 & 0.223 & 0.081 & 20.020 & 0.138 \\
\hline Natural pond & 115.578324 & 37.615915 & 61.9 & 67.3 & 18.6 & 16.7 & 0.13 & 0.029 & 8.2 & 0.07 \\
\hline $\begin{array}{l}\text { The background value of the soil in Hebei } \\
\text { Province }\end{array}$ & & & 68.3 & 78.4 & 21.5 & 21.8 & 0.094 & 0.036 & 13.6 & 1.22 \\
\hline
\end{tabular}

The results showed that the contents of $\mathrm{Cr}, \mathrm{Zn}, \mathrm{Pd}, \mathrm{Cu}$, $\mathrm{Cd}$, and $\mathrm{Hg}$ were $71.3-162.6 \mathrm{mg} / \mathrm{kg}, \quad 51.3-95.8 \mathrm{mg} / \mathrm{kg}$, $25.6-76.4 \mathrm{mg} / \mathrm{kg}, \quad 22.3-63.1 \mathrm{mg} / \mathrm{kg}, \quad 0.11-0.48 \mathrm{mg} / \mathrm{kg}$, and $0.038-0.151 \mathrm{mg} / \mathrm{kg}$ in the sediment of fish ponds in the West Lake of Hengshui Lake, respectively. The contents of all sampling points were lower than the screening values of soil pollution risk of agricultural land in soil environmental quality: risk control standard for soil contamination of agricultural land (trial) (GB 15618-2018)[14].

The contents of As were $13.8-30.7 \mathrm{mg} / \mathrm{kg}$, and the $14 \mathrm{th}$, 15 th, 17 th, 18 th, and 19th sampling points were higher than the screening value of soil pollution risk, but lower than the risk control value in GB 15618-2018.

The contents of Sb were $0.05-0.35 \mathrm{mg} / \mathrm{kg}$. Since there are no relevant contents standard of Sb in GB 15618-2018, the contents of $\mathrm{Sb}$ were analyzed in soil environmental quality: risk control standard for soil contamination of development land (trial) (GB 36600-2018) [15]. The content of each sampling point was lower than the screening value of soil pollution risk of development land in GB 36600-2018.
3.2. Pollution Assessment by the Geoaccumulation Index $\left(I_{\text {geo }}\right)$. The results of $I_{\text {geo }}$ of heavy metal elements in the sediment of the West Lake of Hengshui Lake are given in Table 3. It showed that $I_{\text {geo }}$ of eight heavy metal elements in natural pond was all less than 0 , which can be regarded as uncontaminated in natural pond.

In the fish ponds sediment, the $I_{\text {geo }}$ values of $\mathrm{Zn}$ and $\mathrm{Sb}$ in all sampling points were less than 0 , as given in Table 3, which could be regarded as uncontaminated. The areas with higher $I_{\text {geo }}$ values of $\mathrm{Zn}$ and $\mathrm{Sb}$ concentrated in the south of the West Lake of Hengshui Lake, as shown in Figure 1 (the black spots are fish ponds, and the black regular triangular is natural pond), are adjacent to Jizhou District of Hengshui City. The higher contents of $\mathrm{Zn}$ and $\mathrm{Sb}$ may be related to high population density and more social activities of human beings.

The average values of $I_{\text {geo }}$ about $\mathrm{Cr}, \mathrm{Zn}, \mathrm{As}$, and $\mathrm{Sb}$ were less than 0 in all sampling points of the fish ponds. The average $I_{\text {geo }}$ value of Cr was -0.0594 . But the $I_{\text {geo }}$ values of seven sampling points were higher than 0 , and the $I_{\text {geo }}$ values 
TABLe 3: $I_{\text {geo }}$ of heavy metal elements elements in the sediment at various sampling points in the West Lake of Hengshui Lake.

\begin{tabular}{|c|c|c|c|c|c|c|c|c|}
\hline $\begin{array}{l}\text { Sampling } \\
\text { point }\end{array}$ & $\mathrm{Cr}$ & $\mathrm{Zn}$ & $\mathrm{Pb}$ & $\mathrm{Cu}$ & $\mathrm{Cd}$ & $\mathrm{Hg}$ & As & $\mathrm{Sb}$ \\
\hline 1 & 0.113037897 & -0.530787361 & 0.509194993 & 0.272562018 & 0.641808361 & 0.311201688 & 0.028014376 & -3.267772325 \\
\hline 2 & -0.089312281 & -0.873242858 & 0.259301687 & 0.450984196 & -0.117183539 & 0.768674454 & -0.314873337 & -4.515699838 \\
\hline 3 & 0.327970658 & -0.514923724 & 0.868968474 & 0.948349369 & 1.391830108 & 1.05246742 & 0.185555653 & -3.81526012 \\
\hline 4 & -0.455739 & -1.128209982 & -0.33315 & 0.158605828 & 0.430304 & -0.328622747 & -0.50250 & -4.708344916 \\
\hline 5 & -0.245816767 & -0.907350712 & 0.483828273 & -0.129145151 & -0.117183539 & -0.08246216 & -0.563900885 & -4.056 \\
\hline 6 & -0.522946003 & -1.00737953 & -0.029374602 & 0.301489203 & 0.269839584 & -0.506959989 & -0.415037499 & -4.3457 \\
\hline 7 & -0.20954138 & -0.717872913 & -0.158229668 & -0.063127979 & 0.1823767 & -0.362570079 & -0.453256822 & -3.6088 \\
\hline 8 & -0.121121 & -1.0024 & 0.221433 & & & & -0.172 & \\
\hline 9 & -0.0049 & -0.5648 & & & & & & \\
\hline 10 & -0.367709 & -1.1968 & -0.113 & -0.06774 & -0.3581 & 0.6026 & -0.332 & -4.9307 \\
\hline 11 & -0.33004802 & -0.7567 & 0.26303 & 0.06048 & 0.6418 & 0.859 & -0.396 & -4.34 \\
\hline 12 & -0.2474 & -0.6450 & -0.2833 & -0.5522 & -0.0102 & -0.14 & & \\
\hline 13 & -0.38231 & -0.56123 & -0.038534601 & 0.0044 & 0.3 & 0.026 & -0.462 & -4.708 \\
\hline 14 & 0.447412036 & -0.564861295 & 1.082586418 & 0.863599033 & & 1.483517237 & 0.472232901 & -2.561503528 \\
\hline 15 & 666407273 & & & & & & & -2.81526012 \\
\hline 16 & 0.016104019 & -0.921222887 & 0.259301687 & -0.488960681 & 1.0403 & 0.584962501 & -0.229481846 & -3.9307 \\
\hline 17 & 0.177960582 & -0.622243517 & 0.727540581 & -0.058526077 & 1.182376742 & 1.222392421 & 0.338801913 & -3.708344916 \\
\hline 18 & -0.077376784 & -0.895891597 & 0.655529336 & -0.14369346 & 0.574694165 & 0.245112498 & 0.589669503 & -4.05626822 \\
\hline 19 & 0.315577263 & -0.424885285 & 0.51546759 & 0.021892606 & 1.269839584 & 0.688055994 & 0.46712601 & -2.386416821 \\
\hline 20 & & -1.009847786 & 0.146624914 & -0.458329062 & -0.232660757 & $3.20343 E-16$ & -0.050373523 & -4.345774837 \\
\hline & -0.059403637 & -0.75708665 & 0.346801341 & 0.133690806 & 0.533130883 & 0.468252449 & -0.082134004 & -3.937365064 \\
\hline $\begin{array}{l}\text { Natural } \\
\text { pond }\end{array}$ & -0.218821314 & -0.242392258 & -0.239016775 & -0.291831282 & -0.03527576 & -0.269995762 & -0.395816315 & -1.4173530 \\
\hline
\end{tabular}
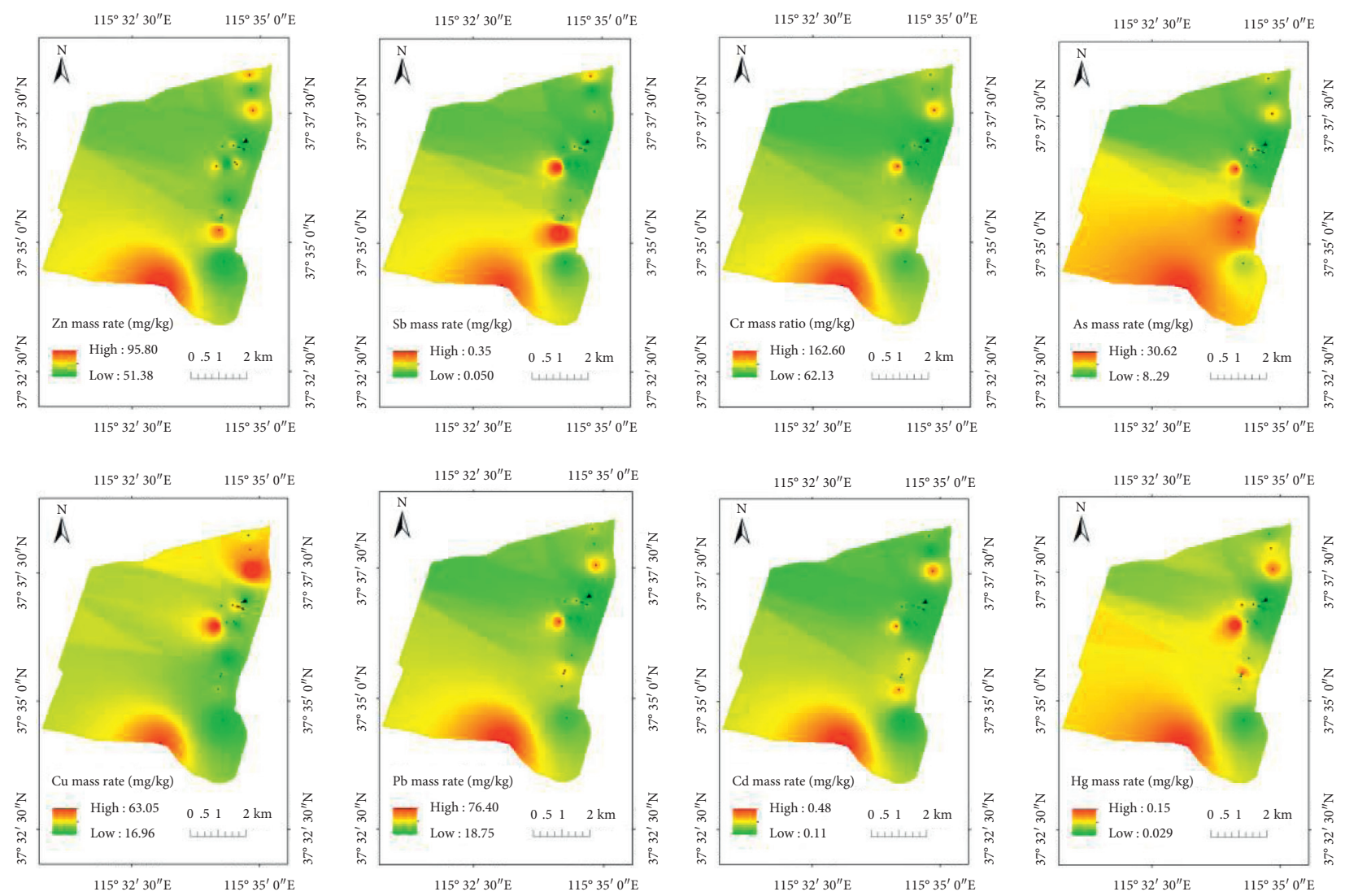

FiguRE 1: Spatial distribution of contents of 8 kinds of heavy metal elements in sediment at 0-50 cm depth in the West Lake of Hengshui Lake. 
of Cr were 0.0161-0.66641, so the pollution class was 1 . It indicated that the seven sampling points were uncontaminated to moderately contaminated by $\mathrm{Cr}$.

The average $I_{\text {geo }}$ values of As was -0.0821 in the fish ponds. But the $I_{\text {geo }}$ values of 8 sampling points were higher than 0 , and the $I_{\text {geo }}$ values of As were $0.02801-0.58067$, so the pollution class was 1 . It indicated that the eight sampling points were uncontaminated to moderately contaminated by As. Similarly, the areas with higher $I_{\text {geo }}$ values of $\mathrm{Cr}$ and As also concentrated in the south of the West Lake of Hengshui Lake, that is, the higher contents of $\mathrm{Cr}$ and As may be related to high population density and more human social activities too.

The average $I_{\text {geo }}$ values of $\mathrm{Pb}, \mathrm{Cu}, \mathrm{Cd}$, and $\mathrm{Hg}$ were higher than 0 in the fish ponds. The average $I_{\text {geo }}$ value of $\mathrm{Pb}$ was 0.3468 . The $I_{\text {geo }}$ values of six sampling points were less than 0 , and the $I_{\text {geo }}$ values of other sampling points were $0.14662-1.24427$. The $I_{\text {geo }}$ values of the 14 th and 15 th sampling points were higher than 1 , so the pollution class was 2. It indicated that the two sampling points were moderately contaminated by $\mathrm{Pb}$. The $I_{\text {geo }}$ values of the other 12 sampling points were $0-1$, and the pollution class was 1 . It indicated that the twelve sampling points were uncontaminated to moderately contaminated by $\mathrm{Pb}$. Therefore, the pollution degree of $\mathrm{Pb}$ was moderately contaminated in general in the fish ponds. The areas with a higher $I_{\text {geo }}$ value of $\mathrm{Pb}$ also concentrated in the south of the West Lake of Hengshui Lake, which means that the higher content of $\mathrm{Pb}$ was also related to the high population density and more human social activities.

The average $I_{\text {geo }}$ value of $\mathrm{Cu}$ was 0.13369 in the fish ponds. The $I_{\text {geo }}$ values of 8 sampling points were less than 0 , and the other sampling points were $0.00441-0.94835$. The $I_{\text {geo }}$ values of these 12 sampling points were $0-1$, and the pollution class was 1 . It indicated that the twelve sampling points were slightly polluted. So, the pollution degree of $\mathrm{Cu}$ was uncontaminated to moderately contaminated in general in the fish ponds. The areas with a high $I_{\text {geo }}$ value of $\mathrm{Cu}$ were scattered. The highest $I_{\text {geo }}$ value was in the northeast corner of the West Lake. It is the junction of Hengshui City and the East Lake and the West Lake of Hengshui Lake, where the traffic flow is large and the population is concentrated. Therefore, it may be related to more human social activities and automobile exhaust.

The average $I_{\text {geo }}$ value of $\mathrm{Cd}$ was 0.53313 in the fish ponds. The $I_{\text {geo }}$ values of 5 sampling points were less than 0 . The other sampling points were 0.08927-1.76734. The $I_{\text {geo }}$ values of the 3 th, 14th, 15th, 16th, 17th, and 19th sampling points were higher than 1 , and the pollution class was 2 . It indicated that the six sampling points were moderately contaminated. The $I_{\text {geo }}$ values of the other 9 sampling points were $0-1$, and the pollution class was 1 . It indicated that the nine sampling points were uncontaminated to moderately contaminated. Therefore, the pollution degree of $\mathrm{Cd}$ was moderately contaminated in general in the fish ponds. The areas with a high $I_{\text {geo }}$ value of Cd still concentrated in the south of the West Lake of Hengshui Lake, that is, the high contents of $\mathrm{Cd}$ were also related to the high population density and more human social activities.
The average $I_{\text {geo }}$ value of $\mathrm{Hg}$ was 0.46825 in the fish ponds, and the $I_{\text {geo }}$ values of 5 sampling points were less than 0 . The $I_{\text {geo }}$ values of other sampling points were $3.2 \times 10^{-16^{-}}-1.48352$. The $I_{\text {geo }}$ values of the 3 th, 14 th, 15 th, and 17 th sampling points were higher than 1 , and the pollution class was 2 . It indicated that the four sampling points were moderately contaminated. The $I_{\text {geo }}$ values of the other 11 sampling points were $0-1$, and the pollution class was 1. It indicated that the eleven sampling points were uncontaminated to moderately contaminated. Therefore, the pollution degree of $\mathrm{Hg}$ was moderately contaminated in general in the fish ponds. The areas with a high $I_{\text {geo }}$ value of $\mathrm{Hg}$ were scattered, mainly concentrated in the high-population density areas such as villages and around the city. So, it was also related to more human social activities.

\section{Conclusion}

(1) In natural ponds, the contents of the other seven heavy metal elements were all lower than BVSH except for $\mathrm{Cr}$, and the contents of eight heavy metal elements were all lower than the soil risk screening value of agricultural land in GB 15618-2018 or the soil pollution risk screening value of development land in GB 36600-2018.

(2) The average contents of $\mathrm{Cr}, \mathrm{Zn}, \mathrm{Pb}, \mathrm{Cu}, \mathrm{Hg}$, and $\mathrm{As}$ were higher than BVSH except for $\mathrm{Zn}$ and $\mathrm{Sb}$ in sediment of the fish ponds at various sampling points in the West Lake of Hengshui Lake. It showed a small amount of heavy metal elements pollutants.

In the fish ponds, the contents of $\mathrm{Cr}, \mathrm{Zn}, \mathrm{Pb}, \mathrm{Cu}, \mathrm{Cd}$, and $\mathrm{Hg}$ were all lower than the standard of the soil risk screening value of agricultural land in GB 156182018. The contents of As in the sediment samples were $8.2-30.7 \mathrm{mg} / \mathrm{kg}$. The contents of As in $5 \mathrm{sam}-$ pling sites were higher than the screening value of soil pollution risk of agricultural land, but lower than the risk control value in GB 15618-2018. The contents of $\mathrm{Sb}$ were $0.05-0.35 \mathrm{mg} / \mathrm{kg}$, which was lower than the screening value of soil pollution risk of development land in GB 36600-2018.

(3) The results of $I_{\text {geo }}$ pollution assessment showed that the sediment samples of the fish ponds in the West Lake of Hengshui Lake were mainly polluted by $\mathrm{Cr}$, $\mathrm{Pb}, \mathrm{Cu}, \mathrm{Cd}, \mathrm{Hg}$, and As. And the pollution degrees of $\mathrm{Cd}, \mathrm{Pb}$, and $\mathrm{Hg}$ were moderately contaminated in general, the pollution degree of $\mathrm{Cu}$ was uncontaminated to moderately contaminated in general, and the pollution degree of $\mathrm{Cr}$ and As was uncontaminated to moderately contaminated in some sampling sites. While in the sediment of natural ponds, the $I_{\text {geo }}$ values of $\mathrm{Cr}, \mathrm{Zn}, \mathrm{Pb}, \mathrm{Cu}, \mathrm{Cd}, \mathrm{Hg}$, As, and $\mathrm{Sb}$ were -1.41735305 to -0.03527576 , which could be regarded as uncontaminated.

The heavy metal pollution in the sediment of the West Lake of Hengshui Lake mainly concentrated in the southern edge area, which is close to Jizhou District of Hengshui City. It may be related to the high population density and more 
human social activities. Therefore, it is necessary to strengthen the discharge control of heavy metal pollutants, the treatment of heavy metal pollutants in sediment, and the long-term monitor of heavy metal pollutants in the sediment. In addition, the analysis showed that the heavy metal pollution in the sediment of the West Lake of Hengshui Lake was mainly concentrated in the fish ponds. There was no heavy metal pollution in the natural pond. So, heavy metal pollution in the fish ponds may be due to the introduction of feeding $[16,17]$. Therefore, the water environment of the West Lake of Hengshui Lake can be effectively improved by cleaning the sediment of fish ponds and "returning fishing to wetland." In the future, several aspects of research should be reinforced, such as the correlation study in the heavy metal pollution in between the West Lake of Hengshui Lake and the surrounding environment, the association of heavy metal pollution between sediment and water in the West Lake of Hengshui Lake, and the comparison of heavy metal pollution between East Lake and West Lake in Hengshui Lake. In addition, the emphasis should be placed on the detection of heavy metal content in sediment, water, and surrounding soil in the Hengshui Lake region.

\section{Data Availability}

The data used to support the findings of this study are available from the corresponding author upon request.

\section{Conflicts of Interest}

The authors declare that they have no conflicts of interest.

\section{Acknowledgments}

This work was supported by the Scientific Research Project of Colleges and Universities in Hebei Province in 2019 (ZD2019310), the Independent Project of the Key Laboratory of Wetland Ecology and Protection of Hebei Province in 2019 (hklz201911), and the Hengshui University High Level Talents Research Start Fund Project in 2018 (2018gc35).

\section{References}

[1] J. Guo, L. Q. Li, D. Z. Huang et al., "Assessment of heavy metal pollution in surface water and sediment of Dongting Lake," Research of Environmental Sciences, vol. 29, no. 1, pp. 44-51, 2016.

[2] L. El Bilali, P. E. Rasmussen, G. E. M. Hall, and D. Fortin, "Role of sediment composition in trace metal distribution in lake sediments," Applied Geochemistry, vol. 17, no. 9, pp. 1171-1181, 2002.

[3] J. J. Rothwell, M. G. Evans, and T. E. H. Allott, "Sedimentwater interactions in an eroded and heavy metal contaminated peatland catchment, Southern Pennines, UK. Water," Air and Soil Pollution: Focus, vol. 6, no. 5/6, pp. 669-676, 2006.

[4] L. I. Min, H. Chen, Z. Sun, and M. A. Gouwei, "Electrokinetic combination remediation of sediment contaminated with complex heavy metals," Chinese Journal of Environmental Engineering, vol. 15, no. 5, pp. 1652-1661, 2021.

[5] D.-R. ai, T. Zhang, J.-S. Bao et al., "Pollution distribution and ecological risk assessment of heavy metals in river sediments from the ancient town of suzhou," Environmental Sciences, vol. 42, no. 7, pp. 3206-3214, 2021.

[6] Z. C. Xu, X. Y. Yang, Y. Wen, G.-H. Chen, and J.-D. Fang, "Evaluation of the heavy metals contamination and its potential ecological risk of the sediments in Beijiang River's upper and middle reaches," Environmental Sciences, vol. 30, no. 11 , pp. 3262-3268, 2009.

[7] S. N. Sin, H. Chua, W. Lo, and L. M Ng, "Assessment of heavy metal cations in sediments of Shing Mun River, Hong Kong," Environment International, vol. 26, no. 5, pp. 297-301, 2001.

[8] N. Wang, Distribution and Seasonal Variability of Mercury in Environment-Medium and Phragmites Australis in Hengshuihu Wetland, China Academy of Forestry Sciences, Beijing, China, 2016.

[9] H. N. Wang, M. Y. Zhang, Z. L. Guo, D. A. Wang, and W. W. Liu, "Distribution of contents of 7 kinds of heavy metal elements in the sediments of Hengshui Lake and their ecological risk assessment," Wetland science, vol. 18, no. 2, pp. 191-199, 2020.

[10] L. Liu, J. W. Zhang, F. F. Chen, S. Sheng, Z. Q. Tian, and J. Wang, "Pollution characteristics and ecological risk assessment of heavy metals in sediment of Hengshui Lake," Journal of Environmental Engineering Technology, vol. 10, no. 2, pp. 205-211, 2020.

[11] M. Zhang, L. Cui, L. Sheng, and Y.-F. Fang, "Pollution and ecological risk assessment of heavy metals in the Hengshuihu Wetland," Wetland science, vol. 5, no. 4, pp. 362-369, 2007.

[12] G. Muller, "Index of geoaccumulation in sediments of the rhine river," GeoJounal, vol. 2, no. 3, pp. 109-118, 1969.

[13] China environmental monitoring station, Background Values of Soil Elements in China, pp. 330-380, China Environmental Science Press, Beijing, China, 1990.

[14] Ministry of ecological environment, Soil Environmental Quality: Risk Control Standard for Soil Contamination Agricultural Land (Trial): GB 15618-2018, China Environment Press, Beijing, China, 2018.

[15] Ministry of ecological environment, Soil Environmental Quality: Standard for Soil Pollution Risk Control of Construction Land (Trial): GB 36600-2018, China Environment Press, Beijing, China, 2018.

[16] S. Qinxuan, Z. Han-qu, J. Wang, Z. Min, and Y. Wei-zhong, "Potential ecological risk assessment and source analysis of heavy metals in surface sediments from aquaculture ponds in Huzhou city," Freshwater Fisheries, vol. 45, no. 6, pp. 80-84, 2015.

[17] S. Xue, "Health innovation," OECD Science, Technology and Industry Scoreboard, vol. 33, no. 6, pp. 156-157, 2013. 